\title{
MARY SHEPHERD ON THE ROLE OF PROOFS IN OUR KNOWLEDGE OF FIRST PRINCIPLES
}

\author{
M. Folescu \\ THIS IS THE PENULTIMATE DRAFT. FORTHCOMING IN NOÛS, 2021.
}

\begin{abstract}
This paper examines the role of reason in Shepherd's account of acquiring knowledge of the external world via first principles. Reason is important, but does not have a foundational role. Certain principles enable us to draw the required inferences for acquiring knowledge of the external world. These principles are basic, foundational and, more importantly, self-evident and thus justified in other ways than by demonstration. Justificatory demonstrations of these principles are neither required, nor possible. By drawing on textual and contextual evidence, I will show that Shepherd should have said that we know the first principles of any science, in general, and that "everything which begins to exist must have a cause", in particular, via intuition, not via reason. Reasoning about such principles can help their self-evidence shine through in certain cases; their justification, and our being justified in believing them, does not come from this reasoning, however.
\end{abstract}

\section{Introduction}

Mary Shepherd, a nineteenth century Scottish philosopher, working in the early modern tradition, argues that we have knowledge of the external world. ${ }^{1}$ Shepherd argues that we know that that the external world exists and is independent of us and, moreover, that we can offer explanations to the best inference with regard to what its true nature is. She takes her arguments to refute Hume's “skeptical system" and thus restore confidence in our scientific practices. ${ }^{2}$ In Essays on the

\footnotetext{
${ }^{1}$ For an argument that Shepherd should be added to the canon as an early modern philosopher, see the practice of having her writings included in collections of writings by early modern women philosophers, e.g. Atherton (1994). For an argument that Shepherd should be added to the canon as a Scottish philosopher, alongside Hume, Smith, Reid, and Stewart, see Boyle (2017).

${ }^{2}$ Reading Shepherd's work, one may form the impression that there are certain key assumptions she makes that beg the question against Hume's views on the causal maxim. Paoletti (2011) and Fantl (2016), for instance, raise such charges. In this paper, I will rely on the explanation of why Shepherd's refutation of Hume's arguments are
} 


\section{Perception of an External Universe and other Subjects Connected with the Doctrine of Causation}

(EPEU henceforth), she explains how this type of knowledge comes about: humans, beginning in infancy, use their latent reasoning powers to justify general principles governing our knowledge of the external world. These reasoning powers are latent, in the sense that any inferences we might be drawing when we employ general principles happen without us being aware. Shepherd, however, contends that, as philosophers, we are able to make such unacknowledged processes explicit and the focus of our study. Her project, in this respect, is a combination of empiricism and rationalism: she believes that our concepts are derived by interaction with the world, via sensory perception, and she thinks that reason helps establish our knowledge of the external world. If successful, her project does more to stave off skepticism than arguments given by some of her post-Humean predecessors, like Reid and Stewart.

This paper examines the role of reason in Shepherd's account of acquiring knowledge of the external world via first principles. I shall argue that reason plays an important, but not foundational role. Certain principles enable us to draw the required inferences for acquiring knowledge of the external world. These principles are basic, foundational and, more importantly, self-evident and thus justified in other ways than by demonstration. ${ }^{3}$ Justificatory demonstrations of these principles are neither required, nor possible. ${ }^{4}$ Given the tradition Shepherd is working in, I will call these principles "first principles" or "axioms". 5 By drawing on textual and contextual evidence, I will

not question-begging developed in Bolton (2019). In addition, I found that the arguments developed in Landy (2020) thoroughly address any lingering worries that Shepherd's views cannot respond to Hume's arguments against causation. I offer more details regarding this issue in $\S 3$ (I thank an anonymous referee for this journal for bringing Landy's excellent paper to my attention.)

${ }^{3}$ I would like to acknowledge right at the start that "self-evidence" is not a simple notion and that it means different things to different people, in different contexts. Throughout this paper, I will leave this notion undefined with the understanding that whatever else it may mean, its meaning includes the idea of "not justified by proof." This is one way in which Locke, whose views Shepherd admires and aims to incorporate in her system (LoLordo (2020, p. 9)), uses the notion. Moreover, this is the most relevant usage for the current paper.

${ }^{4}$ Shepherd does not explicitly approach first principles from this angle. Locke, who explains clearly the distinction between things known by intuition versus those known by demonstration, thought that the axioms of any science are not provable (Essay IV.ix.2-3). This is something that Reid, who takes himself to be addressing Locke's notion of first principles (e.g. EIP VI. 4, 453-454), picks up and further explains (EIP VI. 4, 463). Shepherd was familiar with both Locke's and Reid's views. This provides contextual evidence that this particular characterization of first principles was available to her. I will talk in more detail about Locke, Reid, and the cogency of appealing to Reid's views to reconstruct Shepherd's own system, despite her thorough criticism of his views, in $\S 4.2$.

${ }^{5}$ Shepherd herself talks about first principles as being foundational, as it will become apparent later on (e.g. $E P E U$, Essay 7, 314-316). 
show that Shepherd should have said that we know the first principles of any science, in general, and that "everything which begins to exist must have a cause" ("the causal maxim" henceforth), in particular, via intuition, not via reason. Reasoning about such principles can help their selfevidence shine through in certain cases; their justification, and our being justified in believing them, does not come from this reasoning, however. ${ }^{6}$

This seems to be in tension with Shepherd's view: time and again, she says that reason enables us to know such propositions. I will discuss the relevant passages to explain away this apparent tension. In addition, I will show that my interpretation solves other hard problems that arise from interpreting Shepherd as demonstrating that the causal maxim is true. ${ }^{7}$ These problems are recognized by Fantl (2016) and are a consequence of thinking that Shepherd held that all propositions building up a system of knowledge must be proved, in order for us to have a robust claim at knowing them. I will argue that Shepherd's system has the resources to avoid these problems: intuition, not reason, allows us to know the most fundamental truths justifying our knowledge of the external world. Sometimes, however, it may be difficult for us to immediately access their self-evidence. In such cases, we may be able to reason about them in ways which include (but are not limited to): providing indirect, non-justificatory proofs; providing extrinsic reasons for adopting them (for instance, assessing their fruitfulness for expanding a science); and assessing their relations to other

\footnotetext{
${ }^{6}$ The distinction between intuition and reason is, of course, not entirely precise. "Understanding" was the main operative term, when it came to how we think about things and how we know anything about them, in the early modern era. As Millican (2002, p. 107-108) argues, our understanding (or "reason", as it was sometimes called) was seen as doing double-duty: it was thought to provide "us with insight - genuine understanding of things and perception of their nature, rather than mere thought about them. [In addition, one could emphasize] its function of providing reasons - the basis of rational inference and reasoning." The former aspect is what is usually considered to be the faculty of intuition and its perceptual character is its most exalted feature, from Descartes to Reid. In this vein, Locke clearly excludes intuition from the proper scope of "reason" in his most preferred sense and so does, usually, Hume. Although, Hume is willing to include intuition as an act of the understanding, while also treating "reason" and "the understanding" interchangeably (in the Treatise, there are several places where this is noticeable: $T$ 1.3.6.4/88, 1.3.6.12/92, 1.3.13.13/150, 1.4.1.1/180, 1.4.1.12/186, 1.4.2.1-2/187, 1.4.2.14/193, 1.4.2.46/211, 1.4.2.57/218, 1.4.7.7/268, 2.3.3.2/413, 3.1.1.26/468). Other philosophers of the period, such as Shaftesbury, Hutcheson, and Price, count intuition as itself an exercise of reason (as, again, Millican (2002, p. 107) points out).

${ }^{7}$ The interpretation developed here will go against the standard interpretation, according to which Shepherd proves that it is necessary that every object have a cause and builds her system up after demonstrating this fact. Bolton (2010), Bolton (2019), Fantl (2016), and Paoletti (2011) are the main representatives of the standard interpretation. My interpretation builds on a suggestion from LoLordo (2019, p. 11), who argues that the truth of one of the laws of causation is determined analytically: "we just need to understand what causation is" and then we have no need to demonstrate its truth. This paper offers an explanation of Shepherd's belief that reason still plays an important role in our knowledge of causation and other first principles.
} 
foundational non-provable principles. I will argue that Shepherd uses these strategies to enable us to realize that these principles are self-evident. ${ }^{8}$ Once we do so, these collateral ways of employing our reason about them will no longer be of use. Instead, our reasoning powers can be entirely dedicated to acquiring (inferential) knowledge of the external world.

\section{Knowing the world}

In the first three chapters of the EPEU, Shepherd takes up Hume's challenge and proves that we have knowledge of an external, independent (from us) and continually existing world. ${ }^{9}$ Several things are required for the acquisition of such knowledge. We see this if, as philosophers, we carefully analyze the data. First, sensory perception is at the basis of this knowledge: everyone is able to notice that they have certain perceptions which are as of external objects. Shepherd argues that we know that such sensory perceptions are caused by external things. The reason for this is twofold: first, "everything which begins to exist must have a cause" (i.e. the causal maxim) and second, neither the sensations nor the individuals themselves are such causes. If this type of psychological observation is carried further, one will note that in classifying certain of our sensory perceptions as being like or unlike others, we must realize that these sensations stand in certain relations to one another and, moreover, appreciate that "similar causes must necessarily produce similar effects", so that whenever we are presented with a candle, we will have a perception as of a candle. We are thus able to pair the right causes to their observed effects by using this second law of causation - that I will refer to as "like causes, like effects" hereafter - and an analysis of the relations among our sensations. ${ }^{10}$

Shepherd discusses these two principles - the text in boldface, in the above paragraph - in

\footnotetext{
${ }^{8}$ Strategies like these are employed by scientists in establishing their scientific practice, as I show in $\S 4.2$ and $\S 4.3$. Shepherd, (an amateur) scientist herself, should be placed in this tradition (see Bolton (2010) and LoLordo (2019) for evidence of Shepherd's serious interests in mathematics and chemistry, respectively.)

9"Shepherd proposes a cure," as LoLordo (2020, p. 10) eloquently puts it, to "the malady, which can never be radically cured" (Hume, Treatise 1.4.2.57).

${ }^{10}$ Bolton (2019, p. 141) offers an interesting reconstruction of an argument that explains how this knowledge comes about.
} 
her earlier book, An Essay upon the Relation of Cause and Effect (ERCE, henceforth). Right at the beginning of EPEU, in the Preface, Shepherd states that acquiring knowledge of the external world presupposes our using these two important laws describing the relation of cause and effect. Shepherd also explains how the EPEU is a continuation of the ERCE: to understand how we have knowledge of the external world, we must first understand how the relation of cause and effect works and, hence, what exactly are the principles or laws describing it:

Now the question concerning the nature and reality of external existence can only receive a satisfactory answer, derived from a knowledge of the relation of Cause and Effect. The conclusions therefore, deduced from some of the reasonings used in the former Essay are the instruments employed in conducting the argument in this; - nevertheless it will not be reasoning in a circle, if by carefully defining the nature of internal and external existence, of objects perceived and unperceived, we gain thereby clearer ideas of the method and action of causation.

The analysis, therefore, of the operations of mind from infancy, throws light upon the knowledge we have of cause and effect; and the relation of cause and effect when fully known and established, affords the only method of proof in our power, for the knowledge of external existence. (EPEU, Preface, xii-xvi; original emphasis)

Shepherd's theory of knowledge is housed in her (more general) philosophy of mind. ${ }^{11}$ By learning how our minds work, we understand what justifies our knowledge of the external world. Our minds, if fully working, are equipped to derive this knowledge from interacting with the world. It is a substantial claim that to acquire knowledge of the external world, we must be using the relation of cause and effect. Shepherd argues for this empirically, taking developmental psychology seriously, as indicated by the following passage:

First principles are the perceptions of the corollaries, inclusions, or necessary relations of our simple impressions; and infants who have not a capacity fitted to generate such perceptions, are born idiots. Idiocy appears to be little else, than an incapacity for further perception than what resides in the immediate impressions created by the use of the five organs of sense, and the power of motion.... [Children's] understandings take notice of, (i.e. their latent powers of observations enable them to perceive,) certain simple relations included in those ideas of sensation, which are determined to their minds by the organs of sense. (EPEU, Essay 7, 314-316)

\footnotetext{
${ }^{11}$ This is inspired by the suggestion in Bolton (2019, p. 139) that Shepherd's theory of perception is foundational for her whole system. Landy (2020) makes a similar observation and uses it to show that Shepherd has a strong defense against possible Humean challenges.
} 
Psychology, however, can only take us so far. Shepherd aims to show that our knowledge of the external world, which depends on our knowledge of the relation of cause and effect, is grounded in something more robust than Hume's "inference of habit" or Reid's "natural instinct" (EPEU, Introductory Chapter, 4-5). The success of her system depends on her being able to supply answers to epistemic questions regarding the relation of cause and effect. Do we know that this is a necessary relation? Shepherd believes so and she offers proofs to support this belief. These proofs aim to show that the causal maxim and like causes, like effects are true. Since like causes, like effects may, with some restrictions, be derived from the causal maxim, the proof for the causal maxim is of outmost interest, since Shepherd must show that the causal maxim is justified and that we have access to its justification (on the assumption that the proof of a proposition, if correct, constitutes the justification of that proposition). The other question concerns our access to this knowledge: how is it that we know the two laws describing the relation of cause and effect? Most everyone in the secondary literature argues that, according to Shepherd, it is by demonstrations that we know these principles. In other words, by using our reasoning powers, which allow us to offer demonstrations of the causal maxim etc., we are in a position to know that the relation of cause and effect is necessary. This, in turn, allows us to acquire knowledge of the external world.

This is prima facie supported by Shepherd's stating that it is by reason that we know both the causal maxim and like causes, like effects:

1. That reason, not fancy and "custom," leads us to the knowledge, That everything which begins to exist must have a Cause. (ERCE, 2, 27; original emphasis)

2. That reason forces the mind to perceive, that similar causes must necessarily produce similar effects. (ERCE, 2, 27; original emphasis)

I believe that things are not as straightforward. It is true that Shepherd wants to offer a stronger foundation for knowledge than Humean "custom or fancy" could supply. There are two ways to do so, however: one could attempt to offer demonstrations for such propositions or one could argue that such principles are intuitively known. I will argue that Shepherd recognizes that the causal maxim is foundational and, as such, must be taken for granted, in the absence of any kind 
of justificatory proof. I will argue, moreover, that in passages like the ones above, Shepherd might be interested more in psychology than epistemology: it takes a certain kind of rational work reasoning about such foundational principles - to recognize that they are foundational and, hence, self-justified. ${ }^{12}$

As LoLordo (2019, p. 7) explains, Shepherd fashions herself as Locke's true heir; it is, thus, useful to look at how Locke drew the distinction between intuitive and demonstrative knowledge. ${ }^{13}$ In Locke's classification, intuition allows the mind to immediately perceive the truth of certain propositions. The truth of other propositions, however, must be demonstrated, proven by intervening steps and ideas, which is accomplished by our use of deductive reasoning:

That a Circle is not a Triangle ... Such kind of Truths, the Mind perceives at the first sight of the Ideas together, by bare Intuition, without the intervention of any other Idea; and this kind of Knowledge is the clearest, and most certain, that humane Frailty is capable of. (Locke, Essay, IV.ii.1; original emphasis)

In this Case then, when the Mind cannot so bring its Ideas together, as by their immediate Comparison ... to perceive their Agreement of Disagreement, it is fain, by the Intervention of other Ideas (one or more, as it happens) to discover the Agreement or Disagreement, which it searches; and this is that which we call Reasoning. (Locke, Essay, IV.ii.2; original emphasis)

According to Locke, then, intuition provides the strongest, "most certain" evidence of foundational truths and I think that Shepherd should (and actually might) be following him in this. Shepherd offers a working definition of reasoning that leaves it open whether it is by intuition or demonstration that we know such propositions as the causal maxim:

[T] he very act of reasoning consists in drawing out to observation the relations of things as they are included in their juxtaposition to each other. (EPEU, Introductory chapter, 3; original emphasis)

So, reasoning might help us appreciate that we have intuitive knowledge of principles like the causal maxim, since not all "reasoning" - i.e., exercise of reason - need be inference according to

\footnotetext{
${ }^{12}$ I ask the reader to bear with me while I offer this contextualization and not immediately dismiss my interpretation as seemingly contradicting Shepherd's text. I will show that the benefits - coherence of the system and ability to withstand skepticism - outweigh the risks of apparently misinterpreting the text.

${ }^{13}$ See LoLordo (2019, p. 6) for why this was important to Shepherd.
} 
her. Shepherd (sometimes) writes as though such knowledge were, indeed, intuitive:

[O]therwise [external objects] would each in their turn "BEGIN their own existences", i.e. a relation of ideas would exist [uncaused], which by the youngest minds is not embraced from its involving an intuitive contradiction. Such is the latent reasoning silently generated in the minds of all men, from infancy. (EPEU, Chapter 1, 13-14; my emphasis)

In what follows, I first analyze the problematic consequences of arguing that Shepherd offers proofs that justify our knowledge of the causal maxim. I then discuss an alternative role for reasoning (and proofs) in supporting our knowledge of first principles that grounds our knowledge of the external world. This discussion will provide a way to reconcile the apparent tension in Shepherd's text (illustrated, for instance, by the last two quotes above). Sometimes, to appreciate that we have intuitive knowledge of certain propositions, we must use our reasoning powers to give proofs that illuminate, not justify, their self-evidence.

\section{Reasoning and demonstration}

Shepherd seems to believe that the necessity of the connection between cause and effect can be “demonstrably proven". Thus, we know that external objects exist, given that our minds are stimulated in certain ways by unknown causes whose effects are the very sensory perceptions that represent these objects to us. Passages like the following exemplify Shepherd's position that it is in virtue of our knowing that the causal maxim is true that we learn anything about the external world:

[O]therwise [our sensations] would "begin their own existences;" a proposition which has at large been proved in the former essay [ERCE] to be impossible. (EPEU, Chapter $1,16)$

[The perceptions in question] must be occasioned by unperceived causes affecting [the capacity for sensation in general], the existence of which causes is known, and is demonstrably proven by these their effects. (EPEU, Chapter 1, 18)

[A] priori, we know not what particular effect may arise as the result of any given cause; yet that it is a general proposition capable of demonstration, "that every effect 
must have a cause," and therefore that whatever may be the effect which takes place in such case, the connection between it and its cause, is a necessary connection, and it must necessarily, (in like circumstances,) invariably, and universally inhere in its cause. (EPEU, Essay 8, 327)

Taken at face value, such passages indicate that there should be demonstrations that can be offered in support of the causal maxim and related principles. Several authors have discussed possible reconstructions of demonstrations for the causal maxim (and, in a derived manner, for the second law of causation). Bolton (2010) and Bolton (2019) argue that Shepherd offered several deductive arguments related to causation: (i) a proof of the causal maxim; (ii) a proof in support of our knowledge (such as it is) of particular causes, based on our knowledge of particular effects (namely, our sensory perceptions); and (iii) a proof in support of our conducting generalizations in the natural sciences. The second and third proofs are based on our having evidence for the truth of the causal maxim itself. Thus, it is essential to have a good understanding of what is the rational support for this principle before we can proceed any further in our examination of our knowledge of the external world.

To begin, Bolton argues that the proof for the causal maxim has a lot to do with Shepherd's way of understanding the notions of cause and effect:

A Cause is such action of an object, as shall enable it, in conjunction with another, to form a new nature, capable of exhibiting qualities varying from those of either of the objects conjoined. This is a generation, or creation of qualities not conceived of, antecedently to their existence. .... An Effect is the produced quality exhibited to the senses, as the essential property of natures so conjoined. (ERCE, 2, 63)

The idea is very soon learned, that it is a contradiction to suppose things to BEGIN of themselves; for this idea is occasioned by the impression, (the observation,) that the beginning of every thing is but a change of that which is already in existence, and so is not the same idea, (the same quality,) as the beginning of being, which is independent of previous being and its changes. The two ideas are therefore contrary to each other. ... Changes therefore require beings already in existence, of which they are the affections of qualities. (EPEU, Chapter 8, 170)

Shepherd understands causes to be actions and, as such, to be properties of objects. An object starting to act in a particular way, such that it combines with another object, gives rise to a particular effect. We could all agree that combustion is the effect of fire. On this model of causation, 
combustion, as the effect, is represented as the joining of fire and wood, which is thought to be the cause. ${ }^{14}$ Another way to put it: the cause of combustion, in a particular case, is a particular log's action of getting into union with a particular fire. ${ }^{15}$ As Bolton (2019, p. 135) states, Shepherd "understands 'the beginning of a thing's existence' to mean an action that begins its existence", and not the first moment of existence, as Hume did. ${ }^{16}$ Bolton believes that Shepherd's move is ground-breaking, not question-begging: it reshapes the field by considering that causation can be something else than Hume and most everyone else imagines it to be. I thank an anonymous referee for this journal for asking me to clarify this issue. Thus, it is contradictory to believe that a change in properties of objects can arise without there already being objects having certain properties that are being changed (EPEU, Chapter 8, 170). Bolton (2010, p. 249) emphasizes this point: it is contradictory "to suppose something begins to exist without a cause [because that is just] to suppose [that] an essential property exists and the object to which it is essential does not [yet] exist." And Bolton (2019, p. 135) clarifies: "Shepherd evidently understands 'the beginning of a thing's existence' to mean an action", which is the very notion of a cause, as evidenced by one of the passages quoted above (ERCE, 2, 63). An action cannot exist without it being the action of something. Although Bolton doesn't say so explicitly, the proof for the causal maxim should be characterized as an indirect proof, a reductio that results in a contradiction once the terms of engagement are fully specified: if we understand causation in the terms presented above, it is absurd to believe that

\footnotetext{
${ }^{14}$ For Shepherd, cause and effect are, notoriously, simultaneous. I will talk more about this when I address the interpretation developed in Fantl (2016). For a more recent discussion of this issue, see Landy (2020).

${ }^{15}$ We should not think that wood, fire, etc. are agents, on Shepherd's picture; they simply aren't. Logs can fall in fires, seemingly of their own accord, or they can be put on fire by someone. In both cases, the moment the union between fire and wood is realized is the moment of combustion being realized. It might sound odd to think of the log's getting united with fire as an action of the log, but this is Shepherd's way of drawing our attention to how careful we must be when we think about what is a cause and what its effect. "The coming together of two objects" - whether a "real" action or "just" an instance of motion - is what is essential for causation to happen. I will not address this issue in more detail here; I will think of action as a change in properties - as Shepherd herself does, in EPEU.

${ }^{16}$ Bolton (2019, p. 135) emphasizes, correctly, in my opinion, that this "reasoning does not beg the question, that is, it does not just assume what Hume denies." Shepherd, thus, according to Bolton, does something completely different from Hume's envisioned question-begging opponents: "reading the notion of a thing that begins to exist more sympathetically, Shepherd finds only the difficulty of prying the concept of a thing that begins to exist apart from that of a causally dependent effect. From her point of view, Hume argues in a circle by claiming that a cause precedes its effect in time." Shepherd rejects (and I agree with Bolton that she is entitled to do so) Hume's assumption that cause and effect are temporally successive.
} 
anything can begin its own existence. ${ }^{17}$

Fantl (2016, p. 97-100) also argues that Shepherd offers a proof for the causal maxim. He quotes a passage from $E R C E$, where Shepherd asks us to imagine an empty universe, where nothing can cause anything else to be:

[L]et it be so; let there be nought but a blank; and a mass of whatsoever can be supposed not to require a cause START FORTH into existence, and make the first breach in the wide nonentity around. (ERCE, 2, 35; original emphasis)

This goes back to the idea that Bolton (2010) also defended: the proof for the causal maxim depends on Shepherd's idea that the beginning of the existence of an object is an action of an object, namely an essential property of that object. To suppose that an essential property of an object can exist without the object itself is contradictory. Shepherd uses an instance of this general principle in $E P E U$ (in the passage quoted above, from Chapter 8, 170). However, as Fantl puts it, somewhat rhetorically, "[i]t's not clear why the moving of the universe from a state of lacking such an object to having such an object requires the action of any object - the object itself or any other." (Fantl (2016, p. 98)). But it is clear that such a change must be caused, on Shepherd's view. So, Fantl proposes that perhaps synchronicity - the thesis that causes and their effects exist at the same time - helps justify the causal maxim. He seems to argue that if we did not consider synchronicity as part of the proof for the causal maxim, we would be moving in a circle, regarding the main supposition that "beginning to exist is an action of an object." 18

In addition, we must take into account the fact that Shepherd believes that objects are masses of

\footnotetext{
${ }^{17}$ I am unsure whether Bolton cashes out her promise of offering a reconstruction of a proof for the causal maxim that Shepherd might have given, beyond making it almost an analytical truth that the causal maxim is true, based on Shepherd's definition of "cause" and "object". Maybe this is all the demonstration that can be offered in support of the causal maxim; but there is an air of triviality that hangs around this particular proof. Bolton does offer an argument that makes explicit the latent reasoning that, according to Shepherd, allows us to identify causes for given effects (which are our particular sensations). This argument is valid and, depending on the truth of the empirical premises, it may also be sound. This particular argument, however, relies on our prior knowledge of the causal maxim (Bolton (2010, p. 260) and Bolton (2019, p. 141)) This is not particularly troubling, unless we are supposed to not be epistemically justified in relying on the causal maxim in the absence of a direct proof for it. In other words, without being able to prove directly, by deductive reasoning, that the causal maxim itself is true, our knowledge of the external world isn't justified. What exactly is the direct, justificatory, proof for the causal maxim, then?

${ }^{18} \mathrm{I}$ believe this is a correct observation, since I show in the next section that the causal maxim cannot, strictly speaking, be proven, but that it is one of the first principles that must be taken for granted, if we are to advance in our knowledge of the world.
} 
qualities. ${ }^{19}$ Then, we have all the elements needed to understand why we are justified in believing the causal maxim. As Fantl (2016, p. 99) explains, if a cause precedes its effect, to show that an object necessarily has a cause, we must show that the masses that combine to make up the object necessarily predate the object. If a cause is synchronous with its effect, all that we must show is that the masses that combine to make up the object necessarily are part of the object at the time the object itself exists. Thus, if objects are indeed masses of qualities, then it is obvious that masses of qualities are combined in making up objects (we could say that this is analytically true).

Much like Bolton, Fantl does not offer a reconstruction of a direct demonstration for the causal maxim. He discusses a thought experiment that leads to absurd consequences, given Shepherd's views of causation, objects, and the synchronicity thesis. The alleged proof for the causal maxim is, again, best characterized as a reductio. ${ }^{20}$

Fantl identifies two hard problems with interpreting Shepherd as offering a justification by reductio. First, Shepherd's discussion of synchronicity comes after her argument for the causal maxim (Shepherd talks about synchronicity, for the first time, in ERCE, Chapter 2, 50). This is problematic: it looks like her views of synchronicity are partly derived from the causal maxim itself. Thus, Fantl worries that we would again move in a vicious circle, given that earlier in the book she stated:

Before I proceed further, I wish my reader to grant [the causal maxim] because I mean to make use of it in my further reply to Mr. Hume's doctrines." (ERCE, Chapter 2, 39)

In addition, Fantl (2016, p. 99) argues that relying on the synchronicity of cause and effect to justify the causal maxim "incurs a new argumentative burden." The problem is that construing causation in this way is compatible with there being complete discontinuity between each moment and the next. This is not something that Shepherd wants to allow, since she does claim that the

\footnotetext{
${ }^{19}$ Shepherd advanced this view in several places in ERCE, and she takes it up again in EPEU, when she talks about the fact that this is all set by convention, but that this fact does not take away from the necessary connection between causes and effects. Some representative places can be found in, for instance, ERCE, 2, 53 and in ERCE, 5, 156.

${ }^{20}$ More recently, Landy (2020, p. 5) expands on the idea that this proof is a reductio and also explains that this "argument not only does not beg the question against Hume, but in fact contains plausible objections to his argument, and a plausible alternative to his conclusion." Landy's explanation rests on a passage discussing first principles, a passage I think is key in understanding Shepherd's epistemic project, as I argue in $\S 4.1$.
} 
objects that conjoin to be causes exist before the act of conjoining: "The objects (whose union is necessary to a given result,) must certainly exist, antecedent to such an union" (ERCE, 2, 57; original emphasis). According to Fantl, this is needed to guarantee a causal link between each moment and the next. But, he points out that once we understand causal relations as being synchronous, we lack an argument that such links $d o$ indeed exist. So, Shepherd seems to just stipulate, rather than demonstrate, that there is a causal link between each moment and the next. ${ }^{21}$

Given these issues, I propose we start anew: if the best we can do to support the causal maxim is to offer indirect, reductio proofs that have the air of triviality about them, maybe we should reconsider the role such proofs have in the economy of establishing a system of knowledge. This will allow us to better appreciate the exact role of reason in our acquiring knowledge of the external world..$^{22}$

\section{Reasoning and self-evidence}

My proposal for dissolving the issues raised in the previous section starts by considering the causal maxim (and maybe cognate principles) as a first principle, an axiom, if we like, in a system of knowledge of the external world. This section addresses two related questions: first, how does this help advance the project? Second, is there enough (con)textual evidence for thinking that the causal maxim is a first principle? To answer the first question: thinking that the causal maxim is an axiom releases us from the need to supply a demonstration as evidence of its truth; we are able to just take its truth for granted. To answer the second question, I will be partly guided by Shepherd's views on mathematics, where she explicitly takes like causes, like effects as a foundational, axiomatic principle. She argues that mathematics is "but one branch of physics" (EPEU,

\footnotetext{
${ }^{21}$ Fantl (2016, p. 100) remarks that after trying to offer demonstrations for the causal maxim (seemingly talking about himself and Bolton), we are none the wiser than we were when Paoletti (2011, p. 51) stated that Shepherd never demonstrated that cause and effect are necessarily connected, but always took it for granted that the physical universe is fully deterministic.

${ }^{22}$ The suggestion that there is something wrong with reductio proofs, in general, need not be thought widely out of place: intuitionistic logic, for instance, recognizes that reductio poofs can only be used to prove negative statements. As we will see in the next sections, Reid thought that reductio proofs are "lesser than" direct, apodictical demonstrations. This will be relevant for constructing a charitable interpretation of Shepherd's views.
} 
Essay 5, 278) and that a sort of causal induction is the main means of working out mathematical proofs. ${ }^{23}$ In justifying mathematical propositions, she contends, we always rely on like causes, like effects. Since this principle, in turn, relies, for its justification, on the causal maxim, according to Shepherd, I argue that she should have explicitly stated that the causal maxim itself is an axiomatic first principle, whose truth we are justified to believe without needing any further demonstrations to support it.

\subsection{First principles}

Shepherd seldom talks about first principles. A representative passage, quoted earlier, comes late in the $E P E U$ :

First principles are the perceptions of the corollaries, inclusions, or necessary relations of our simple impressions; and infants who have not a capacity fitted to generate such perceptions, are born idiots. Idiocy appears to be little else, than an incapacity for further perception than what resides in the immediate impressions created by the use of the five organs of sense, and the power of motion. (EPEU, Essay 7, 314-315)

There are Lockean and Reidian undertones here. ${ }^{24}$ Recall that Locke believed that to know

\footnotetext{
${ }^{23}$ See Bolton (2010, p. 254) for an exposition of Shepherd's views on the foundational role of inductive proofs in mathematics.

${ }^{24}$ Shepherd is familiar with the views of both philosophers: she approves of Locke's writings and she criticizes Reid's take on several of the issues she writes about. It is worth noting that Locke and Reid seem to agree a lot on how to understand first principles: what they are, how they are known, and what kind of evidence (if any) we can cite in their support. Although Reid believes that first principles are a lot more useful in advancing our knowledge than Locke (e.g. Reid, EIP VI. 4, 454), both believe that first principles are self-evident propositions, known by intuition, not in need or even "capable of any proof" (cf. Locke, Essay IV.ix.3 and Reid, EIP VI. 4, 452). In addition, Reid believes that we have some ways of cementing our belief that certain propositions that seem to have "the light of truth" in themselves do indeed have it, even though, for him, just as for Locke, our knowledge of first principles is, in some sense, passive (cf. Locke (Essay IV.ii.1: "[intuitive] Knowledge is irresistible, [it] forces itself immediately to be perceived, as soon as ever the Mind turns its view that way; and leaves no room for Hesitation, Doubt, or Examination, but the Mind is presently filled with the clear Light of it.") and Reid (EIP VI. 4, 452: "It is not in our power to judge as we will. ... [T] here are other propositions which are no sooner understood than they are believed. The judgment follows the apprehension of them necessarily, and both are equally the work of nature, and the result of our original powers. There is no searching for evidence, no weighing of arguments; the proposition is not deduced or inferred from another; it has the light of truth in itself, and has no occasion to borrow it from another.") Given that Locke and Reid agree on the essential features of first principles and given Shepherd's avowed respect for Locke's views, I believe it is fair to use some of Reid's views on first principles to support an interpretation that strengthens Shepherd's system, even though she disagrees with Reid in other respects. (It may be worth mentioning that other authors have identified strong points of connection between Locke's and Reid's views, despite the fact that Reid's criticisms of Locke may sometimes give us a different impression. For more, see Nichols (2003) and Freitas (2017).)
} 
something intuitively means to perceive the agreement or disagreement of two ideas immediately. We intuitively know color and shape incompatibilities, in addition to appreciating that larger quantities are indeed larger than smaller ones (Essay IV.ii.1, quoted in $\S 2$ ). It is generally thought that Locke believed that the axioms of mathematics, logic, and maybe even morals, are known in this way: immediately, without proof. He writes, for instance: [f]or in this, the Mind is at no pains of proving or examining, but perceives the Truth, as the Eye doth light, only by being directed toward it (Essay IV.ii.1). ${ }^{25}$ In the passage above, Shepherd talks about immediacy in relation to our impressions (i.e. sensory perceptions) only. But, maybe, the relations among these simple perceptions are also immediately taken note of: she believes that young children, for instance, do appreciate that perceiving something to be wholly of one color excludes the possibility of it being wholly of any other color (EPEU, Chapter 8, 170-171). Children's "understandings take notice of certain simple relations included in those ideas of sensation. ... And this they very soon do, as readily as they distinguish by which organ it is that any new impression of sense is conveyed." (EPEU, Essay 7, 315-316.) She takes this to be part of the psychological development of typical children. ${ }^{26}$

Shepherd, thus, believes that to acquire knowledge of the external world, we need more than just the bare information provided by our senses. We will not be able to acquire such knowledge unless we have access to certain first principles. Shepherd doesn't explicitly say that such principles ground our knowledge of the external world; I believe, however, that it is fruitful, for her overall project, to think that they have this role. To better appreciate this, let us look at one of the most detailed accounts of first principles that Shepherd had access to: Reid's. ${ }^{27}$

\footnotetext{
${ }^{25}$ Weinberg (2016) gives a thorough explanation and critique of the role and functioning of Lockean intuitive knowledge (see, in particular, Chater 3, Part I).

${ }^{26}$ Landy (2020, p. 4 and p. 13) uses Shepherd's reliance on empirical psychology to show that she has a good defense against the claims of begging the question against Hume's views of causation: any such objection from Hume would rely on his theory of mental representation and Shepherd has good arguments to show that this theory is incorrect.

${ }^{27}$ I want to stress that Shepherd does not criticize Reid's views on first principles; neither does she explicitly endorse them. Appealing to Reid's position on first principles, which I take to be not only a criticism, but also an explication and expansion of Locke's views, allows me to offer a charitable rational reconstruction of Shepherd's system. If I am right that Locke's position is an ancestor to both Reid's and Shepherd's views, we have the proper contextual tools to understand the latter's contributions, which go beyond offering non question-begging arguments against Hume's views on causation.
} 
Several aspects of Reid's view of the first principles of common sense are relevant here. ${ }^{28}$ First, Reid abides by Locke's distinction between intuitive and demonstrative knowledge, arguing that some of our judgments are intuitive, while others are grounded on argument. Certain propositions are such that:

[They] are no sooner understood than they are believed. The judgment follows the apprehension of them necessarily, and both are equally the work of nature, and the result of our original powers. There is no searching for evidence, no weighing of arguments the proposition is not deduced or inferred from another; it has the light of truth in itself. (EIP, VI. 4, 452)

Such propositions are called "axioms, when they are used in matters of science; and on whatever occasion they are used, are called first principles" EIP, VI. 4, 452). ${ }^{29}$

I believe it is no accident that Shepherd talks about first principles in the way she does. Shepherd thought that to function well, the human mind must judge certain propositions as true, immediately upon its acquiring sensory perceptions. Unless we are born with "a capacity fitted to generate such perceptions" - of certain first principles - we are gravely lacking in cognitive power, according to her, as it is obvious from the passage describing the typical psychological development of human beings (EPEU, Essay 7, 315). It is true that Shepherd criticizes Reid for what she takes as his relying on "instinct" or "nature" to explain the foundations of knowledge. Her main frustration, here, seems to be that, according to Reid, we have no further way of explaining how these instincts come about, e.g. "it is not necessary to have recourse to any instinct or principle of nature, which we know nothing of" (EPEU, Essay 7, 316). She is correct that Reid thinks that appreciating the truth of the first principles is the work of "nature and the result of our original powers" (EIP, VI. 4, 452). Shepherd, however, seems to be missing the key point here: our minds are structured in such ways as to understand, immediately upon consideration, the truth of the first principles. In other words, Reid seems to be saying something very close to what Shepherd herself

\footnotetext{
${ }^{28}$ For an excellent explanation of what first principles are and how they work in Reid's epistemology, see Van Cleve (2015), in particular Chapter 11 and Appendices V.

${ }^{29}$ We should note that this passage is compatible with the view that we could use proofs by reductio to learn that the propositions we deem to be the axioms of a system are true. Reid says as much in a later passage that I will discuss momentarily.
} 
says: typically developed human minds will have a faculty (this is the import of Reidian "original powers") whose role is to illuminate the truth of such foundational propositions. ${ }^{30}$

Shepherd is not alone in misunderstanding Reid in this way: some of his contemporaries and immediate followers took his reliance on "instinct" and "common sense" as being key aspects of his system. And some of his critics, most notably Kant, took this to mean that a system like Reid's will stop any philosophical explanation in its tracks and, instead, will appeal to the views of the untrained commoners to "demonstrate with zeal and impudence that which [Hume] never thought of doubting." 31 A reading like this is invited by Reid's insistence that no definitions or explanations of why exactly our minds work in the way they do can be offered; instead, the most we can do, according to him is to carefully interpret our empirical observations and construct verifiable generalizations based on such observations (for a representative passage, in this respect, see his EIP, II. 1, 71). Shepherd is trying to go beyond this impasse, as she offers many inferences to the best explanation to construct her system. The problem, of course, is that we often have no way of verifying such inferences. ${ }^{32}$ In the case under scrutiny, however, Shepherd does not offer any explanation for why typically developed human minds work in the way they do; she relies on empirical psychology to just posit that this is how they work. Empirical observations of this kind do not explain why something happens; they record that something does, indeed, happen in a particular way. Reid, being an avowed Newtonian, as a principle of methodology, points this out whenever the opportunity arises. ${ }^{33}$ Shepherd's views converge with Reid's on this particular issue,

\footnotetext{
${ }^{30}$ Here is a representative passage describing Reid's use of "original natural powers of our minds": "I apprehend that the word faculty is most properly applied to those powers of the mind which are original and natural, and which make a part of the constitution our the mind. There are other powers which are acquired by use, exercise or study, which are not called faculties, but habits. There must be something in the constitution of the mind necessary to our being able to acquire habits, and this is commonly called capacity" (EIP I. 1, 21). The main contrast Reid draws is between mental abilities that are built into how our minds work (faculties and capacities) and those we acquire (habits, for whose acquisition certain capacities must already exist). The former are "original" and "natural" in the sense that they are a constitutive part of the human mental architecture, whereas the latter are not. For a presentation on the relationship between original versus acquired powers of the mind, see Copenhaver (2020).

${ }^{31}$ See Kant (1950, p. 06-07) for his views on what he took to be the foundations of experimental philosophy. For more on what exactly is under dispute, see Beanblossom (1988).

${ }^{32}$ Reid, in particular, warns against using unverified and unverifiable hypotheses to offer explanations of things that cannot be explained without our having access to the true essences of things (EIP I. 3, 51-52). For a discussion of what Reid's view of essences has to do with knowledge, see Folescu (2016).

${ }^{33}$ When commenting on why he endorses Newton's "No more causes" rule, Reid states: "When Newton had shown the admirable effects of gravitation in our planetary system, he must have felt a strong desire to know its cause. He
} 
even though she is willing to push back on his general methodology in regards to our knowledge of the external world. The beauty of her system consists in her offering possible ways to go beyond such limitations (in combining reason and empirical study in the ways she does), without her overstepping the bounds of what is available to be known by typically developed human beings.

To reinforce this point, it is useful to compare Reid's thinking that "the power of judging in self-evident propositions ... may be compared to the power of swallowing our food .... common to the learned and the unlearned" (EIP, VI. 4, 453) with Shepherd's insistence "that the child, as well as the peasant, (and even the philosopher when withdrawn from his books)" (EPEU, Essay 7, 319) all regularly, albeit unconsciously, use the causal maxim to ground their various beliefs about the external world. Recourse to first principles to gain knowledge of the external world is, thus, part and parcel of how typically developed human minds work. Despite their methodological disagreements, I would argue that Shepherd should have recognized that a position like Reid's not only supports her own view, but also allows her to further develop it, in order to formulate a strong response to a skeptical challenge like Hume's. ${ }^{34}$

\subsection{Knowledge and justification of first principles}

First principles are essential for our acquiring knowledge of the external world. This conclusion, however, raises two additional questions: one, psychological, the other, epistemological. How do we know these principles? What justifies our knowledge of them? ${ }^{35}$ The relation between

could have invented a hypothesis for this purpose, as many had done before him. But his philosophy was of another complexion." (EIP I, 3, 51.)

${ }^{34}$ I do not argue that Shepherd, unknowingly, but nonetheless fully, adopted Reid's view, or even that she should have endorsed all of his views regarding first principles, in general, and causation, in particular. I believe that Reid too quickly dismisses Hume's challenges. By contrast, if we allow that Shepherd may have used the distinction between demonstrating for justification and demonstrating for better appreciating the truth of first principles that I identify Reid as drawing, we will be in a position to understand her original solution to the access problem regarding the principles of causation. It may be true that we intuit them (although it is quite vexing, to this day, to explain what exactly intuition is and how it is supposed to work), since it seems to Locke, Reid, and Shepherd that we do. In addition, there is strong extrinsic support that we can appeal to when trying to convince a skeptic about causation. By offering non-justificatory demonstrations of first principles, Shepherd takes Hume seriously and goes beyond Reid in closing the explanatory gap we have regarding our knowledge of such principles.

${ }^{35}$ Of course, these questions aren't original with Shepherd, and her (and others') treatment of the issues doesn't stop philosophers from asking them again and again. (For a recent insightful explanation of what it is to be self-evident (thus, in need of no further justification) and how it is that we know the self-evident, see Shapiro (2009).) Teasing out 
psychology and epistemology is well-known: just because certain propositions are justified, it doesn't mean that we know them, if we don't have access to their justification. There cannot be knowledge without justification; justifications, however, can exist without our being able to access them.

The notion of proof seems to be the golden standard of epistemic justification. A proof or a demonstration of a proposition is constructed by deductive reasoning; demonstrations give "evidence of the truth of a proposition" under consideration (Reid, EIP, VII. 4, 566). ${ }^{36}$ Being able to provide a demonstration of a proposition will curtail all skeptical doubts; in that moment, knowledge of the truth of the proposition will have been secured. In such cases, psychology and epistemology walk closely together: how do we know the truth of a demonstrated proposition? In the most obvious cases, we know it by being able to understand the proof. ${ }^{37}$ From a psychological point of view, then, being able to access the proof (with understanding) will satisfy us of the certainty of our belief of the truth of that proposition. How is the truth of the proposition justified? By the existence of the proof itself; this is pure epistemology.

Shepherd recognizes this; that is why she is in search of a demonstration for the causal maxim (and related principles). By providing such a demonstration, we would be in a position not only to assuage the skeptic, but also to explain how it is that we know this principle. She seems to believe that Hume didn't do enough on the epistemic side: what Shepherd takes as his insistence that it is simply human nature to believe such principles in the absence of there being any justifications for them doesn't sit well with her goal of setting skeptical doubts aside once and for all. She also seems to think that Reid didn't do enough on the psychological side: what Shepherd takes as his insistence that no explanations of how our minds work can be offered doesn't sit well with her

the details of Shepherd's view is important for keeping psychology and epistemology distinct, something that some of her predecessors - Hume and, in a lesser measure, Reid - didn't do that well.

${ }^{36}$ This issue, of course, does not originate with Reid. I am citing his take on it, as a very clear expression of something known from at least Euclid's time.

${ }^{37}$ Knowledge is, of course, varied and complicated. What I describe in the main text is the "easy", ideal, straightforward case; there are numerous other, more complicated ones, where we could be said to derivatively know a proposition by trusting the experts that there is a proof of it, which other experts understand and approve of (for instance, I might be said that I know that Fermat's last theorem is true, because I know that a (widely accepted) proof of it exists, even though I am not in a position to produce or understand the proof). Shepherd takes our knowledge of the causal maxim to be one of the easy cases. 
scientific convictions.

The problem with Shepherd's insistence that we must provide demonstrations for all the principles needed to secure knowledge of the external world is that it is impossible to do so. There is simply no way to offer a proof of all the propositions used in even the most exact of our sciences. Reid offers another relevant insight here: we would be faced either with a regress to infinity or with vicious circularity if we tried to prove all the propositions of the science under consideration. We must recognize that some propositions "are themselves supported by none" other; they are the beginnings of all proofs and knowledge. Reid's main point here is that "all knowledge got by reasoning must be built upon first principles" (EIP, VI. 4, 454-455). He, of course, believes that such principles are self-evident: they are justified in themselves, they require no other justification. Moreover, they can be given no other justification: "it is contrary to the nature of first principles to admit of direct or apodictical proof" (EIP, VI. 4, 463; original emphasis). ${ }^{38}$

As any contemporary philosopher of mathematics can attest, the notion of self-evidence is a vexed one. Maddy (1988a), Shapiro (2009) and others point out that the idea of self-evidence goes hand-in-hand with the idea of psychological obviousness and certainty for some mathematicians. Gödel, famously, believed that the axioms of set theory "force themselves upon us as being true" (Gödel (1964, p. 484)). Frege, by contrast, at least as read by Burge (1998), elucidates a purely epistemic notion of self-evidence, attributed to basic principles that are seen as "neither capable nor in need of proof" (Frege $(1884, \S 3))$. These two late-nineteenth century examples show, however, how closely intertwined psychology and epistemology are. It is easy to confuse the evidence that first principles have, in themselves, with the evidence that an individual uses to explain her believing them, at one time or another. This, of course, isn't helped by Locke, (which is where Frege's words come directly from), ${ }^{39}$ who talks about our ways of knowing and types of justification of the first principles in the same breath:

\footnotetext{
${ }^{38}$ Reid, of course, is not the first to think of foundational principles and consider them self-evident. One main reason for appealing to his views is that he seems to distinguish well between psychology and epistemology: certain propositions are self-evident independently of our way of knowing them, as the quote from the main text indicates.

${ }^{39}$ Although, as Burge (1998, p. 313) points out, Frege might have come to this phrase by reading Leibniz's New Essays on Human Understanding, which state Locke's views verbatim, before criticizing them.
} 
Knowledge, as has been shewn, consists in the perception of the agreement or disagreement of Ideas: Now where that agreement or disagreement is perceived immediately by it self, without the intervention or help of any other, there our Knowledge is selfevident. (Essay IV.vii.2)

[W]e have the Knowledge of our own Existence by Intuition ... we perceive it so plainly and so certainly, that it neither needs, nor is capable of any proof. (Essay IV.ix.2-3)

For Locke, then, the mark of self-evidence is our knowing certain propositions in a particular way: immediately, intuitively.

More importantly for the present discussion, though, is Locke's understanding of the notion of proof. Demonstrations (or proofs) seem to be important not so much for providing justifications of the propositions whose truth they confirm, but for helping our minds become aware of this. A demonstration removes all doubt "by the Intervention of the intermediate Ideas, [and] the Agreement or Disagreement is perceived" (Locke, Essay IV.ii.5). It is in cases where we cannot just "see" that two ideas agree with one another, that we need a demonstration, which is supplying an intermediary idea that agrees with each of the original ones we were considering. As Owen (2007, p. 406) explains, for Locke, "a demonstration is a chain of ideas, such that each idea in the chain is intuitively seen to agree or disagree with its neighbours. A demonstration is a series of intuitions."

Shepherd, who, like Locke, is emphasizing "the special role of reason and the special dignity of human beings as rational creatures, ${ }^{40}$ is well aware that supplying such chains of intuitions in the case of the causal maxim will satisfy certain Humean worries. If such a chain can be produced to explain our belief in the causal maxim, then maybe it will be enough for everyone who understands the terms to agree that nothing can begin its own existence. So, Shepherd is doing just that: she is supplying something that looks like a demonstration. The question, though, is whether this demonstration has the role of actually making the justification for the causal maxim explicit (epistemology), in addition to firming up our belief in this principle (psychology). This is a complicated question to answer, not in the least because Shepherd is interested both in epistemology and psychology.

\footnotetext{
${ }^{40}$ LoLordo (2020, p. 9)
} 
I believe that Reid's views can help us begin to answer this question. He takes Hume's insight seriously that it is not by an "inference of reason" that we know the causal maxim and, in turn, he lists it as the second metaphysical first principle (Reid, EIP, VI. 6, 497). Thus, the causal maxim is an axiom that is self-justified (not by reasoning). It belongs to a class of principles that are deemed to be principles of necessary truths - namely, those that "are necessary and immutable, whose contrary is impossible" (Reid, EIP, VI. 5, 468). This is the crux of the matter: entertaining the contrary of the causal maxim is impossible; this will always lead to absurd consequences. We may try to do this, explicitly, and this could prove helpful, since, although first principles do not:

admit of direct or apodictical proof, yet there are certain ways of reasoning even about them, by which those that are just and solid may be confirmed, and those that are false may be detected. ... A first principle may admit of a proof ad absurdum. In this kind of proof, which is very common in mathematics, we suppose the contradictory proposition to be true. We trace the consequences of that supposition in a train of reasoning; and if we find any of its necessary consequences to be manifestly absurd, we conclude the supposition from which it followed to be false; and therefore its contradictory to be true. (EIP VI. 4, 463)

By constructing indirect proofs, which are not meant to justify self-evident principles, we could better understand which propositions should be classified as first principles. It is noteworthy, however, that some first principles may not admit of even indirect, by reductio proofs, so this type of proof cannot be used to find all first principles. Reid lists other procedures that may help with better classifying proposition as first principles. He also recognizes that some first principles are extremely obvious, and that may be a reason for not admitting of any kind of proofs. Self-evidence, for him, is a more robust notion than obviousness or psychological certainty: some things that are obvious, and hence may seem self-evident, may prove to be debatable or outright false. ${ }^{41}$ Trying to offer a reductio (or other type of reasoning) to bolster our belief in such cases is a good procedure to apply in building up our system of knowledge.

Let us now recall what Shepherd presents as a proof of the causal maxim: a reductio ad absurdum, where she invites us to assume that something can begin to exist without it being caused.

\footnotetext{
${ }^{41}$ Maddy (1988a, p. 481) puts it best: "assumptions once thought to be self-evident have turned out to be debatable, like the law of the excluded middle, or outright false, like the idea that every property determines a set."
} 
Nothing more than understanding the terms is required for us to appreciate that it is an absurdity to claim that the contrary of the causal maxim can be true. The thought experiment Shepherd presents is making it explicit what causation actually is. This thought experiment, however, does not introduce any new intermediary idea(s): there is no chain of intuitions, in which pairs of ideas are seen to agree with each other. This is a way to reason about first principles that is available to anyone who has the right abilities, according to Shepherd, and it can answer a certain type of skeptical challenge: why should I believe that this very first principle is true? By supplying a proof that confirms our belief in it, we can be assured that everything else resting on the causal maxim (namely everything in the natural and, according to Shepherd, mathematical sciences) is firmly grounded from an epistemological point of view.

\subsection{Benefits of reasoning about the axioms}

Thinking about exactly what role proofs have in our understanding and deciding which propositions are indeed first principles, in a particular science, or in the theory of knowledge, itself, does not reduce to a simple verbal dispute, as it may appear from the considerations discussed above. One may wonder why exactly it matters whether we offer direct proofs for a proposition to justify it or indirect proofs (and other types of reasoning) that just enable the self-evidence of a proposition shine through. Isn't a proof just a proof and the rest, as the saying goes, just semantics?

(More) contemporary philosophy of logic and mathematics may help us better appreciate the importance of the distinction between direct and indirect proofs. Echoing Reid, albeit probably unknowingly, Frege remarked that "it is in the nature of mathematics to prefer proof, where proof is possible" (Frege $(1884, \S 2)$ ). Certain things, as we have seen, are taken to be foundational, epistemically speaking. Direct, justificatory proofs, in the case of the first principles, are impossible. It is, however, crucial to have procedures for appreciating which propositions can be added to a science, in order to initiate and then extend it. Part of this might be an attempt to offer some type of reasoning that would make the self-evidence of certain presumed-to-be axioms shine through. ${ }^{42}$

\footnotetext{
${ }^{42}$ Frege would think that proofs by reductio just show that the presumed-to-be axiom is, in effect, a theorem, not a
} 
If this is possible, the story goes, these propositions are embraced and used to derive other useful principles that could not have been otherwise demonstrated.

Maddy (1988a) and Maddy (1988b), in a tour de force surveying "how the unproven can be justified" in a substantial portion of set theory (having to do, primarily, with Zermelo-Fraenkel with choice ("ZFC" henceforth), the continuum problem, small large cardinals, measurable cardinals, the determinacy hypothesis, and large large cardinals) observes that there are, by and large, two ways of thinking about the axioms of set theory. By comparing the axioms of ZFC with others, they are thought to "follow directly from the concept of set, [being] somehow "intrinsic" to it (obvious, self-evident), while other axiom candidates are only supported by weaker, "extrinsic" (pragmatic, heuristic) justifications". Maddy, however, points out that this distinction does not neatly separate the axioms of ZFC from the rest. The fact that these particular axioms are held in such high regard is little more than a historical accident. When one looks at the historical details, it seems that "the first axioms for set theory were motivated by a pragmatic desire to prove a particular theorem", and not various foundational matters (Maddy (1988a, p. 482)). On this interpretation, it is not their supposed privileged epistemic status (their alleged self-evidence) that marked these as the founding principles of set theory. It is, one may call it, their "fruitfulness" in setting up a new branch of mathematics that helped select them. ${ }^{43}$

If we agree with this reasoning, bolstered with countless other examples of how mathematicians have offered extrinsic reasons for adopting even the most basic of the axioms (Maddy (1988a, p. 484)), we will be in a position to appreciate that Shepherd is an early representative of the position that a science prefers proof, where proof can be given. Whenever a proposition, in mathematics,

basic principle. It may be surprising to think that Frege himself employed other forms of extrinsic, holistic, evidence to bolster our confidence in the self-evidence of some of the presumed-to-be axioms. Nonetheless, according to some authors, he did just that. Burge (1998, p. 328), for instance, argues that Frege is guided in the discovery of self-evident principles by a methodology that is "explicitly pragmatic and contextualist." Jeshion (2001, p. 969) also interprets Frege as using collateral evidence for learning that certain propositions are self-evident: "To identify a proposition as not needing proof ... we need to systematize our knowledge and see whether the proposition can fulfill the role of an axiom ... It does so by being fruitful, by enabling the derivation of all known mathematical knowledge and by affording means of generating more." See also Shapiro (2009) for a discussion of the importance of this historical fact.

${ }^{43}$ As Eagle (2008, p. 83) points out, though, fruitfulness has its perils: it can be too restrictive and hence prevent science from progressing in the "right" way. For instance, as Eagle points out, "a contradiction is extremely fruitful in logical consequences, though at the cost of emptying the universe of objects." Everything follows from a contradiction, but what follows applies to nothing. 
is proposed as an axiom, mathematicians are searching for reasons explaining why it should be adopted. For the case at hand, the causal maxim admits of an indirect proof, which depends on the definition of causation. What Shepherd does is offer arguments to persuade us of the fruitfulness of adopting the causal maxim as a basic principle.

Shepherd, as a declared Lockean, doesn't confuse intuition and reasoning; she just thinks that we need to offer some additional support for the causal maxim, to help us understand that we are entitled to make recourse to this principle in our theory of knowledge. As previously indicated, she seems to regard this principle as part of our psychology, but Shepherd also wants to show that, epistemically speaking, this is a sound principle. In addition to giving an indirect proof, Shepherd also shows that this first principle is necessary for science. This is giving a different type of extrinsic support, something that mathematicians often do. Notably, Zermelo did this in the case of the axiom of choice: in the 1908 axiomatization, he provided a list of seven theorems that rely on it (Shapiro (2009, p. 198)). While this didn't show that the axiom itself is true, or made explicit the notion of self-evidence that Zermelo was working with, it showed that an axiomatic system that adopted this axiom would lead to a richer set theory. Echoing Reid, Zermelo believed that one cannot offer a direct proof of the axiom of choice and "therefore cannot compel anyone to accept it apodictically" (Zermelo (1908, §2.a); my emphasis). Self-evident principles cannot be proven directly, but looking at our mathematical practices, we will note that the axiom of choice has been frequently used and that "[s]uch an extensive use of a principle [that can't be proved] can be explained only by its self-evidence" (Zermelo (1908, §2.a); original emphasis.) Notably, a similar idea is part of Shepherd's strategy: she uses the causal maxim to further show how the latent reasoning that we all undergo when we learn anything about the world can be made explicit (the reconstruction offered in Bolton (2010, p. 259-60) and, again, in Bolton (2019, p. 141) makes this apparent).

Thinking that proofs and other types of reasoning may be employed not to justify a given proposition, but to allow its self-evidence to shine through, in the relevant cases, allows us to respond to Fantl's objections to the reasoning offered by Shepherd in ERCE in support of the 
causal maxim.

Recall that the first worry Fantl raised concerned a threat of circularity: in offering her justification for the causal maxim, Shepherd relies on the synchronicity thesis, which she derives relying on the causal maxim (Fantl (2016, p. 99)). This is, indeed problematic, if we think that the proof Shepherd gives is supposed to justify the causal maxim. If, by contrast, we think that what Shepherd does in offering that reductio is rather spelling out the details of an analytic argument, this worry should not trouble us anymore. Analyticity goes both ways; it is symmetric. Neither the synchronicity thesis nor the causal maxim has any kind of metaphysical or epistemic primacy, in such a case. Both the causal maxim and the synchronicity thesis are, in effect, first principles, which cannot be justified by offering direct proofs. They are self-justified. Their self-evidence might be made apparent by offering reductio proofs (as it is the case for the causal maxim) or by other rational means: for instance, assessing their relationships with other first principles.

The other, more substantive worry that Fantl (2016, p. 99) raised concerned the discontinuity between each moment and the next. He believes that the proof for the causal maxim doesn't go through without recourse to the synchronicity thesis (which, in turn, would make the whole proof circular, as discussed above). But, once we adopt the synchronicity thesis, we have no grounds to show that moments are not discontinuous. This may be so, if Shepherd were offering a proof to justify, by demonstration, the causal maxim. If, however, we think of what she is doing as offering a way to reason about an axiom, to give, thus, extrinsic reasons in support of this first principle, then synchronicity will be seen to play no justificatory role. This dissolves this particular problem of thinking that the causal maxim isn't epistemically grounded. Of course, on further scrutiny, it may turn out that cause and effect are synchronous. It may, indeed, be the case that the universe is required to be deterministic, as Paoletti (2011) argues that Shepherd took for granted. These, however, are further metaphysical claims, which are not required for understanding why everything that begins to exist must have a cause. If, indeed, we understand Shepherd's attempt here as spelling out the details of an analytical argument, we realize that this objection loses its cogency: 
no further epistemic grounding is required or possible in support of the causal maxim. ${ }^{44}$ The causal maxim, along with the synchronicity thesis, are grounded just by their being self-evident principles. So, we are released from whatever worries stemmed from the search for such grounds.

\section{Conclusion}

In this paper, I discussed what is the structure of our knowledge of the external world, according to Shepherd. The relation of cause and effect is paramount in establishing that we have such knowledge. Shepherd offers arguments to prove that this relation is necessary and explains why we should think that we have robust knowledge of the laws describing this relation. Thus, in order to understand how we acquire knowledge of the external world, we must be clear that and how we know these laws of causation, namely the causal maxim and like causes, like effects. Shepherd believes that they ground our knowledge of the external world. What exactly grounds them and, in particular, the causal maxim?

If my analyses and arguments are correct, the causal maxim is a foundational principle; my interpretation of Shepherd's text highlights all the reasons for which she should have said so explicitly. I showed that the option of endorsing the idea that the causal maxim is self-evident was available to her (via Locke and Reid) and discussed some benefits for thinking that this is part of her project. Whatever proofs and other types of reasoning Shepherd offered in support of the causal maxim, I argued, were designed to allow its self-evidence to shine through, not to provide justification. This is in line with theories proposed in contemporary epistemology of mathematics, partly derived by observation of the mathematical practice. My interpretation brings coherence to Shepherd's system and shows that intuition and reasoning have complementary roles to play in the acquisition of the knowledge of the external world. ${ }^{45}$

\footnotetext{
${ }^{44}$ This is akin to thinking about the axioms of mathematics as being definitions: "they tell us what we are talking about", which is a common way of thinking in contemporary philosophy of mathematics (Shapiro (2009, p. 175)).

${ }^{45}$ Despite appearances, writing philosophy papers is rarely an isolated activity, so I would like to thank several people for helping me write this article, in one way or another. I first learned of Mary Shepherd's philosophy in graduate school, when Jen Liderth, a fellow student, organized a reading group on the Essays on the Perception of an External Universe and other Subjects Connected with the Doctrine of Causation. Then, in 2018, I was part of the
} 


\section{Primary Works}

Hume, D. (2007). A Treatise of Human Nature. ( D. F. Norton and M. J. Norton, eds.). Oxford: Clarendon Press. (Original work published in 1739). Abbreviated as $T$.

Locke, J. (1975). An Essay Concerning Human Understanding. (P. H. Nidditch, ed.) Oxford: Clarendon Press. (Original work published in 1700). Abbreviated as Essay.

Reid, T. (2002). Essays on the Intellectual Powers of Man. (D. R. Brookes \& K. Haakonssen, eds.) Edinburgh: University Press. (Original work published in 1785). Abbreviated as EIP.

Shepherd, M. (1824). An Essay upon the Relation of Cause and Effect Controverting the Doctrine of Mr. Hume Concerning the Nature of that Relation; with Observations upon the Opinions of Dr. Brown and Mr. Lawrence Connected with the Same Subject. London: T. Hookham. Abbreviated as ERCE.

Shepherd, M. (2020). Essays on the Perception of an External Universe and other Subjects Connected with the Doctrine of Causation. (A. LoLordo, ed.) Oxford: Oxford University Press. (Original work published in 1827). Abbreviated as EPEU.

\section{References}

Atherton, M. (Ed.) (1994). Women Philosophers of the Early Modern Period. U.K.: Hackett Publishing Company.

Journal of the History of Philosophy Masterclass on Shepherd's philosophy, organized by Don Garrett. I would like to thank him and the other Mary Shepherd enthusiasts, Chloe Armstrong, Ruth Boeker, Daniel Collette, Kristopher G. Phillips, and Curtis Sommerlatte, for presenting, criticizing, and amending Shepherd's views, so that they all made sense to a convinced Reidian like myself. I would like to thank my graduate students, who took the seminar on Shepherd's philosophy in the Fall 2019. The lively exchanges in that seminar, especially those between Selwyn Griffith and Argon Gruber, kept my own enthusiasm going. In 2020, I presented some of this material at the Eastern meeting of the American Philosophical Association. I would like to thank Christia Mercer, the organizer of that session, for inviting me to give a talk on Shepherd's philosophy, alongside Don Garrett and Antonia LoLordo. I would like to thank everyone who participated in that symposium for raising poignant questions and, especially Christia, Don, Antonia, Keota Fields, and members of the audience. Don and Antonia read and commented extensively on previous versions of this paper, and I am very grateful to them for doing so. Eileen Nutting and Zeynep Soysal wrote long emails advising me on the status of axioms in mathematics and the various access problems that can ensue with regard to first principles. I am grateful to both for their generosity. I would like to thank Alex Radulescu for closely reading, extensively commenting, and discussing these issues with me before writing the final draft of this manuscript. I presented some of this material in two Zoom venues and benefitted a lot from interactions with other Zoom participants. In this regard, I would like to thank Anat Schechtman, who, over the summer of 2020, organized the Early Modern Virtual Workshop Series. I am very grateful to everyone who read my paper and gave me comments, especially Sebastian Bender, Ruth Boeker, Patrick Connolly, Jonny Cottrell, Julia Jorati, Daniel Moerner, Kathryn Tabb, Ericka Tucker, Anat Schechtman, and Stephan Schmid. Finally, I would like to thank Jen Foster and Cassie Finley for organizing The Cogtweeto Philosophy Twitter Workshop Series and for inviting me to present this material. I am grateful for everyone who logged in to Zoom to learn more about Shepherd's views on proofs and, especially, to Philipp Schwarz, for raising a very interesting question about the intellectual relationship between Reid and Shepherd. Last, but certainly not least, I am very grateful for the comments I received from two anonymous referees for this journal. 
Beanblossom, R. E. (1988). Kant's Quarrel with Reid: The Role of Metaphysics. History of Philosophy Quarterly, 5(1), 53-62.

Bolton, M. B. (2010). Causality and Causal Induction: The Necessitarian Theory of Lady Mary Shepherd. In K. Allen, \& T. Stoneham (Eds.) Causation and Modern Philosophy, (pp. 242-261). Routledge: Florency, KY.

Bolton, M. B. (2019). Lady Mary Shepherd and David Hume on Cause and Effect. In E. O’Neill, \& M. P. Lascano (Eds.) Feminist History of Philosophy: The Recovery and Evaluation of Women's Philosophical Thought, (pp. 129-152). Switzerland: Springer Nature.

Boyle, D. (2017). Expanding the Canon of Scottish Philosophy: The Case for Adding Lady Mary Shepherd. Journal of Scottish Philosophy, 15(3), 275-293.

Burge, T. (1998). Frege on Knowing the Foundation. Mind, 305-347.

Copenhaver, R. (2020). Reid on Language and the Culture of Mind. Australasian Journal of Philosophy, https://doi.org/10.1080/00048402.2020.1753086.

Eagle, A. (2008). Mathematics and Conceptual Analysis. Synthese, 161(1), 67-88.

Fantl, J. (2016). Mary Shepherd on Causal Necessity. Metaphysica, 17(1), 87-108.

Folescu, M. (2016). Thinking About Different Nonexistents Of The Same Kind. Philosophy and Phenomenological Research, 93(3), 627-649.

Frege, G. (1884). Foundations of Arithmetic. Evanston, IL: Northwestern University Press, 1968.

Freitas, F. V. (2017). Thomas Reid on the first principles of speculative, moral and political knowledge. (Doctoral Dissertation). NNT : 2017PA01H221. tel-01784238: Université PanthéonSorbonne - Paris I; Universidade federal de Minas Gerais.

Gödel, K. (1964). What is Cantor's Continuum Problem. In P. Benacerraf, \& H. Putnam (Eds.) Philosophy of Mathematics, (pp. 470-485). Cambridge: Cambridge University Press, 1983, second ed.

Jeshion, R. (2001). Frege's Notions of Self-evidence. Mind, 110, 937-976.

Kant, I. (1950). Prolegomena to Any Future Metaphysics. Ed. by Lewis White Beck. Indianapolis: Bobbs-Merril. (Original work published in 1783).

Landy, D. (2020). Shepherd on Hume's Argument for the Possibility of Uncaused Existence. Journal of Modern Philosophy, 2(1), p. 13.

LoLordo, A. (2019). Mary Shepherd on Causation, Induction, and Natural Kinds. Philosopher's Imprint, 19(52), 1-14.

LoLordo, A. (2020). Introduction to Mary Shepherd's Essays on the Perception of an External Universeary shepherd's essays on the perception of an external universe. In A. LoLordo (Ed.) Essays on the Perception of an External Universe, (pp. 1-24). Oxford: Oxford University Press. 
Maddy, P. (1988a). Believing the Axioms. I. The Journal of Symbolic Logic, 53(2), 481-511.

Maddy, P. (1988b). Believing the Axioms. II. The Journal of Symbolic Logic, 53(3), 736-764.

Millican, P. (2002). Hume's Sceptical Doubts Concerning Induction. In P. Millican (Ed.) Reading Hume on Human Understanding: Essays on the First Enquiry, chap. 4, (pp. 104-153). Oxford: Oxford University Press.

Nichols, R. (2003). Reid's Inheritance from Locke, and How He Overcomes It. Journal of the History of Philosophy, 41(4), 471-491.

Owen, D. (2007). Locke on Judgment. In L. Newman (Ed.) The Cambridge Companion to Locke's 'Essay Concerning Human Understanding', chap. 14, (pp. 406-435). Cambridge: Cambridge University Press.

Paoletti, C. (2011). Restoring Necesssary Connections: Lady Mary Shepherd on Hume and the Early Nineteenth-century Debate on Causality. I Castelli di Yale, 11(11), 47-59.

Shapiro, S. (2009). We Hold these Truths to Be Self-evident: But what Do We Mean by That? The Review of Symbolic Logic, 2(1), 175-207.

Van Cleve, J. (2015). Problems from Reid. Oxford: Oxford University Press.

Weinberg, S. (2016). Consciousness in Locke. Oxford: Oxford University Press.

Zermelo, E. (1908). Neuer Beweis für die Möglichkeit einer Wohlordnung. Mathematische Annalen, 65, 107-128. 